\title{
A study of the flood events in Cyprus
}

\author{
K. Savvidou, K. A. Nicolaides, S. C. Michaelides, A. Orphanou, M. Charalambous, and S. Adamou \\ Meteorological Service, Nicosia, Cyprus
}

Received: 20 December 2007 - Revised: 5 May 2008 - Accepted: 15 May 2008 - Published: 9 July 2008

\begin{abstract}
Almost every year, localised and in some cases more widespread floodings affect parts of Cyprus, causing damages to properties destruction to infrastructure and housing and sometimes the loss of human life. Various factors such as the meteorological situation and type and intensity of precipitation, the geomorphology, the geology and the human intervention to geomorphology are responsible for flood events. In the present study, only the meteorological situation and the associated mechanisms are examined in an attempt to gain the essential knowledge for improvement of local weather forecasts.

The study period covers a thirteen-year period, from 1994 to 2006, in which 43 cases of flooding were reported, mainly over urbanized areas. The dominant favorable weather conditions for flood events are either the existence of a depression or weather conditions of convectional type. According to these two factors, the flood events were classified into two categories; the "instability" category which includes isolated flood events of short duration, and the "depression" category which includes widespread flood events of long duration.
\end{abstract}

\section{Introduction}

From a climatological point of view, the area of the Mediterranean is characterized by a long, warm and dry period (Blanchet, 1976; Maheras, 1985) generally lasting from May to September, and a relatively wet and cold period, lasting from September to May.

During the cold season, baroclinic depressions reach the area of Cyprus (El-Fandy, 1946; Kallos and Metaxas, 1980) mainly from a westerly direction (Michaelides et al., 2004; Nicolaides, 2005). Fewer depressions enter this area from other directions, while only isolated cases are generated or regenerated in situ (Michaelides et al., 2004; Nicolaides, 2005). Flood events are typical during the cold season and the main contributor is baroclinic instability.

During the hot season, the area is under the influence of the SW Asia thermal low and baroclinic depressions are very rare. Consequently the mean sea level pressure is relatively low, with marked high temperatures, mainly inland; also, enhanced sea breezes penetrate several kilometers inland acting as a humidity transportation mechanism, during daytime. Under these circumstances and with increasing thermal instability, local thunderstorms are common with some even resulting in floods, mainly inland.

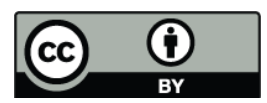

Correspondence to: K. Savvidou (lefele@cytanet.com.cy)

\section{Data and methodology}

The study period covers a thirteen-year period, from 1994 to 2006, in which 43 cases of flooding were reported in Cyprus, mainly over urbanized areas. These events were grouped, in accordance with the associated synoptic situation, into two categories, namely, the "instability floods" and the "frontal depressions floods".

In order to identify the characteristics of each of the above categories, several dynamic and thermodynamic parameters were examined. The dynamic parameters examined were a static stability index, the relative vorticity, the divergence of the horizontal wind vector and the distribution of the fields of temperature and geopotential heights over various isobaric surfaces, one day before the event (D-1), on the day of the event (D) and the following day (D+1). The numerical forms of the relationships for calculating these parameters are given by Nicolaides et al. (2004). The data used for the necessary mathematical calculations are the NCEP/NCAR global analyses for 00:00 UTC with a grid length of $2.5^{\circ} \times 2.5^{\circ}$ and the area of the calculations is bounded by the meridians $20^{\circ} \mathrm{W}$ and $50^{\circ} \mathrm{E}$ and the parallel circles $20^{\circ} \mathrm{N}$ and $65^{\circ} \mathrm{N}$. For brevity, only selected mean spatial distributions for D+1 are presented.

Several thermodynamic parameters of the troposphere over the island of Cyprus, for the respective dates were also calculated, using the radiosonde data from the station of Athalassa $\left(35^{\circ} 1^{\prime} \mathrm{N}, 33^{\circ} 4^{\prime} \mathrm{E}\right)$. Rainfall data, daily and hourly,

Published by Copernicus Publications. 


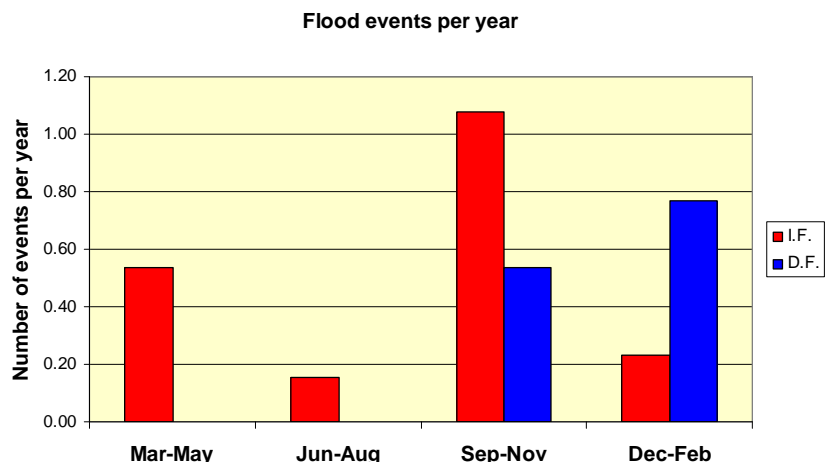

Figure 1. Seasonal distribution of flood events.

Duration of the flood

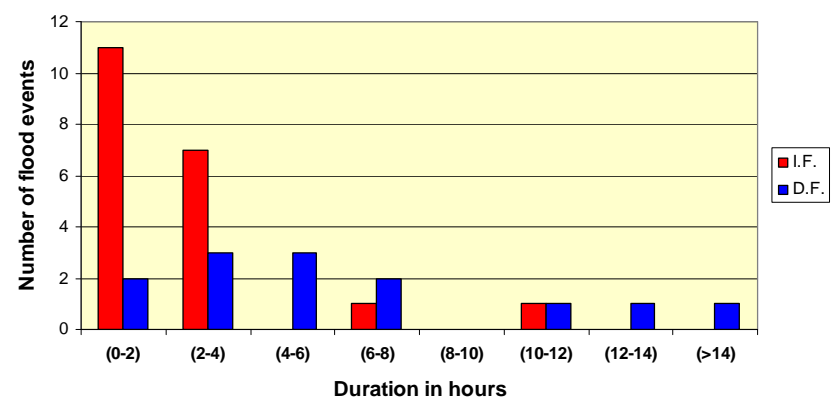

Figure 2. Duration of flood events.

from the Cyprus Meteorological archive were also used in order to reveal some general characteristics of the events, such as the seasonal and spatial distribution, duration and amount of precipitation (Houssos and Bartzokas, 2006). For the spatial distribution i.e. number of flood events per affected area, the flood events were grouped into 5 geographic areas, representing the respective administrative districts: Paphos, Lemesos, Larnaka, Ammochostos and Lefkosia.

\section{Results}

\subsection{General characteristics}

During the study period, 43 cases of flooding were reported. Out of these, 17 cases were caused by frontal depression (i.e. identified as D.F.) and 26 cases were caused by instability weather type (i.e. identified I.F.).

The D.F. events are typical during the winter with $59 \%$ of the cases and during the autumn with $41 \%$ of the cases. The I.F. events can be occurred throughout the year with maximum frequency during autumn, with $54 \%$ of the cases, and during spring, with $27 \%$ of the cases (Fig. 1).

From the proportion between the daily precipitation of the flood event and the monthly precipitation normal, the $47 \%$ of the events result in precipitation above the $100 \%$ of the monthly normal, the $22 \%$ of the events result between 50

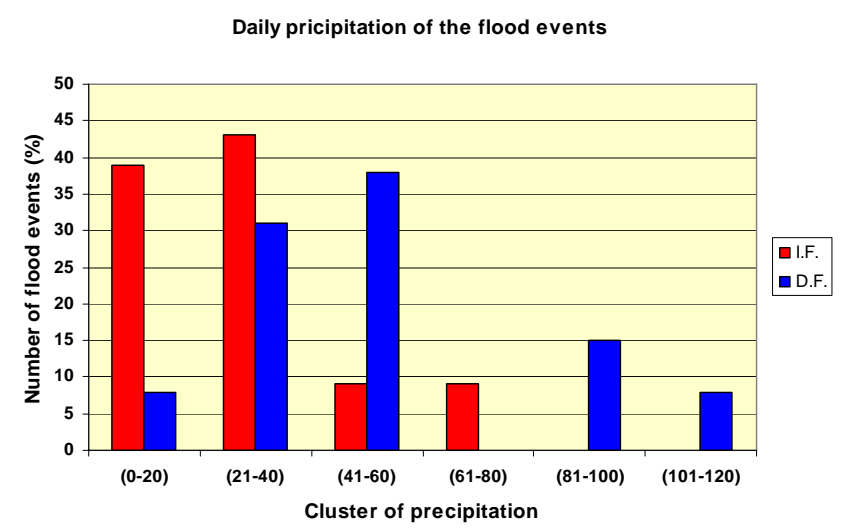

Figure 3. Daily precipitation of flood events.

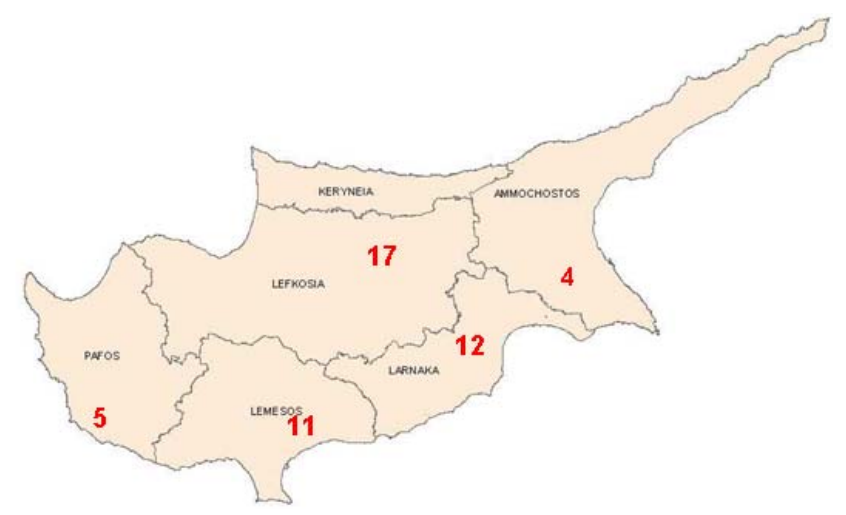

Figure 4. Number of flood events in various districts.

$100 \%$ of the monthly normal while the $31 \%$ of the events result in less than $50 \%$ of the monthly precipitation normal.

For the $69 \%$ of the D.F. cases, the daily precipitation (Fig. 3) values are classified between $21-60 \mathrm{~mm}$, and for the $23 \%$ of the cases, between $81-120 \mathrm{~mm}$. Most of the I.F. cases, namely $82 \%$, have daily precipitation amounting up to $40 \mathrm{~mm}$ and only $18 \%$ of the cases have daily precipitation ranging from 41 to $80 \mathrm{~mm}$.

The hourly precipitation study reveals that for the $91 \%$ of the cases for the D.F. events and for the I.F. events is up to $40 \mathrm{~mm}$ but with slightly different distribution; $59 \%$ of the I.F. cases and $33 \%$ of the D.F. cases have hourly precipitation up to $20 \mathrm{~mm} / \mathrm{h}$, while $32 \%$ of the I.F. cases and $58 \%$ of the D.F. cases have hourly precipitation between ranging from 20 to $40 \mathrm{~mm} / \mathrm{h}$.

The duration of the D.F. events is considerably higher than the duration of the I.F. events; $60 \%$ of the D.F. events have duration above $4 \mathrm{~h}$, while $90 \%$ of the I.F. events have duration up to $4 \mathrm{~h}$ (Fig. 2).

The favourable areas for flooding are the larger cities such as Lefkosia, Larnaka, and Lemessos (Fig. 4). Isolated cases of flooding were reported in some villages in Lefkosia, Larnaka and Ammochostos districts. 
(a)

(b)
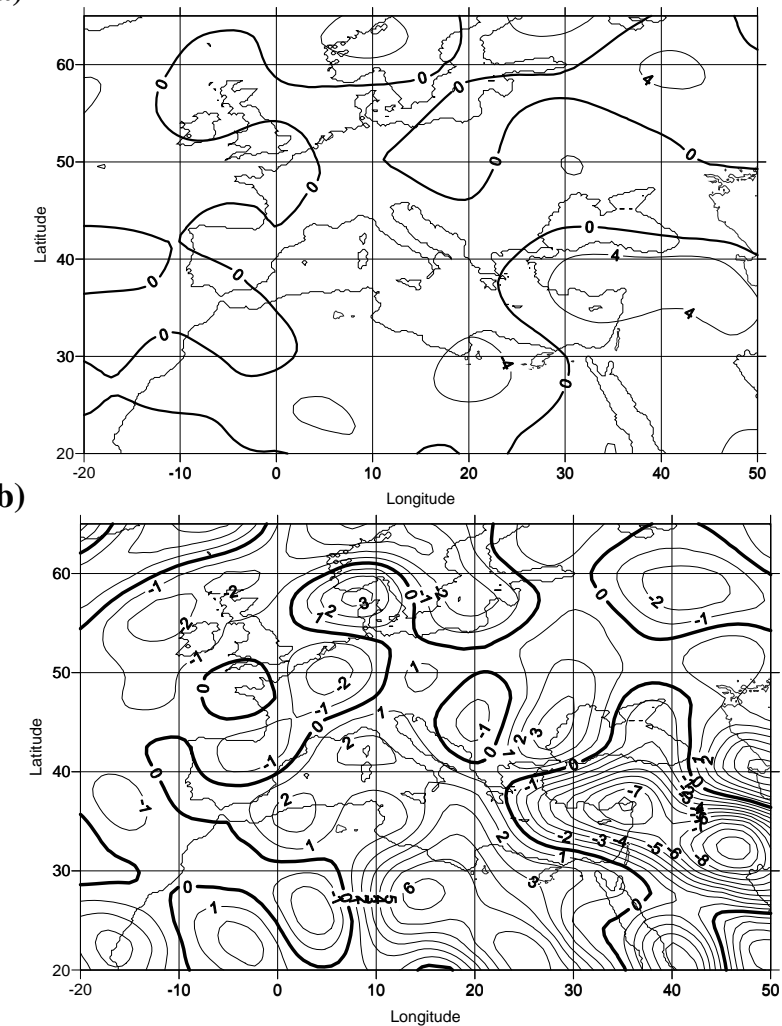

Figure 5. Field of divergence of the horizontal wind vector over the isobaric surface of $300 \mathrm{hPa}\left(10^{-6} \mathrm{~s}^{-1}\right)$ (a) and $850 \mathrm{hPa}$ (b), for the D.F. events on D+1.

\subsection{Dynamic study}

\subsubsection{Frontal depression flood events}

On D-1 a confluent trough is found in all levels over the central and eastern Mediterranean with its axis over Greece. The axis position has a westward tilt from lower to higher levels, indicating that the system is a developing one. The area of Cyprus is situated on the cold site of the jet stream, an area favorable for cyclogenesis. The vorticity field at the isobaric layer of $300 \mathrm{hPa}$ obtains maximum values over the central Mediterranean and southeast of Cyprus. From the field of divergence of the horizontal wind vector over the isobaric surfaces of $850 \mathrm{hPa}$ and $300 \mathrm{hPa}$, the areas of the central and the east Mediterranean are areas of lower tropospheric convergence (negative values) and upper tropospheric divergence (positive values), with maximum values over the area of Greece. This coupling leads to upward motion and formation of cloud.

On D the trough axis is found further east and the values of the various fields noted an increase. On the isobaric surface of $850 \mathrm{hPa}$, a cut-off low develops, with its center over south Aegean, while warm advection is noted over the area of Cyprus, thus enhancing the cyclogenesis over this latter area. (a)

(b)
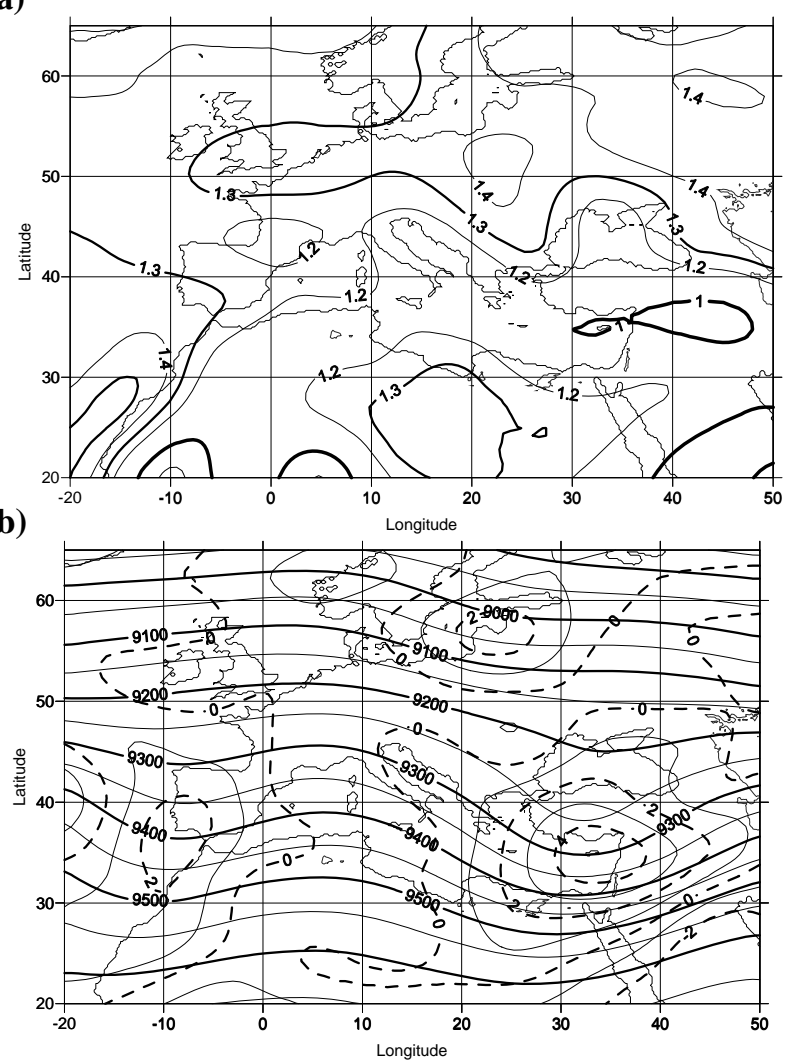

Figure 6. $850 \mathrm{hPa}$ static stability index in $\mathrm{K}^{2} \mathrm{~s}^{-1}$ (a) and $300 \mathrm{hPa}$ vorticity field in $10^{-5} \mathrm{~s}^{-1}$ (b), for the I.F. events on $\mathrm{D}+1$.

On D+1 (Fig. 5a, b) due to warm advection and positive vorticity advection over the eastern Mediterranean the various field over the Cyprus area noted their maximum (absolute) values. Also the height noted a significant decrease between $\mathrm{D}$ and $\mathrm{D}+1$; around $500 \mathrm{gpm}$ over $300 \mathrm{hPa}$, around $400 \mathrm{gpm}$ over $500 \mathrm{hPa}$ and $200 \mathrm{gpm}$ over $850 \mathrm{hPa}$.

\subsubsection{Instability flood events}

On $\mathrm{D}-1$, the distribution of the static stability index over the $850 \mathrm{hPa}$ surface reveals a relatively unstable lower tropospheric area over the maritime regions between Italy and Cyprus. Subsequently, this area moves to the east and decrease in coverage, thus on D+1 (Fig. 6a) is located over Cyprus. From the field of divergence of the horizontal wind vector over the isobaric surface of $850 \mathrm{hPa}$ from $\mathrm{D}-1$ to $\mathrm{D}+1$, the area of the east Mediterranean is characterized as an area of lower tropospheric divergence, dumping upwards motions.

On D-1, an upper trough is noted at all levels over the eastern Mediterranean. Cold advection over the area of Cyprus is observed on the isobaric level of $850 \mathrm{hPa}$. The axis position has a westward tilt from lower to higher levels, 
Table 1. The mean values of the indices.

\begin{tabular}{cccccc}
\hline $\mathrm{TT}\left({ }^{\circ} \mathrm{C}\right)$ & $\mathrm{KO}\left({ }^{\circ} \mathrm{C}\right)$ & $\mathrm{K}\left({ }^{\circ} \mathrm{C}\right)$ & $\mathrm{WBZ}(\mathrm{ft})$ & $\mathrm{Hc}, \mathrm{Tc}\left(\mathrm{ft},{ }^{\circ} \mathrm{C}\right)$ & $\mathrm{CAPE}(\mathrm{J} / \mathrm{Kg})$ \\
\hline 49 & -5 & 25 & 7138 & $19704,-42$ & 793 \\
Moderate & Severe & Moderate & Severe & Moderate & Weak \\
\hline
\end{tabular}

Table 2. Thresholds of the indices.

\begin{tabular}{llll}
\hline & Weak & Moderate & Severe \\
\hline TT & $<45$ & $45-55$ & $>55$ \\
KO & $>6$ & $2-6$ & $<2$ \\
K & $<25$ & $25-35$ & $>35$ \\
HcTc & $<17000,>-35$ & $17000-22000,-35$ to -45 & $>22000,<-45$ \\
CAPE & $0-1000$ & $1000-2500$ & $>2500$ \\
WBZ & $<5000,>11000$ & $5000-7000,9000-11000$ & $7000-9000$ \\
\hline
\end{tabular}

indicating that the system is a developing one. From D-1 to $\mathrm{D}+1$, the trough moves gradually to the east at all levels, with its axis located over Cyprus on D+1. The temperatures and the heights over the various levels and over the area of Cyprus exhibit a small decrease during the three day period of about $1-2^{\circ} \mathrm{C}$ and $10-20 \mathrm{gpm}$, respectively. The relative vorticity field over the $300 \mathrm{hPa}$ isobaric layer has its maximum value in the area of the trough axis in all days. On D+1 (Fig. 6b) the maximum value which is around $5 \times 10^{-5} \mathrm{~s}^{-1}$ is located over Cyprus, enhancing the cyclonicity of the upper tropospheric levels. Comparing with the frontal depression flood events, the values of the vorticity field are slightly greater.

The above analysis illustrates that the contribution of the dynamic parameters to the I.F. events is small; it seems that the most dominant processes in this category of flood events are those associated with the diabatic thermal heating, as most of the events $(58 \%)$ occur within the warm period and during midday and afternoon $(83 \%)$.

\subsection{Thermodynamic study}

For the thermodynamic analysis of the atmosphere, various indices and parameters were calculated for each flood event using the radiosonde data from Athalassa station $\left(35^{\circ} 1^{\prime}\right.$, $33^{\circ} 4^{\prime}$ ) at 12:00 UTC. The indices and the parameters are the K Index, the Total Totals Index (TT), the Convective Available Potential Energy (CAPE), the Wet Bulb Zero degree isotherm (WBZ), the KO index, the Cloud Top Temperature (Tc) and the vertical extend of the convective cloud above freezing level (Hc) (see Michalopoulou, and Jacovides, 1987; König, 2002; Jacovides and Yonetani, 1990; University of Wyoming, 2007).

The indices were studied in two different ways. Firstly, the indices were classified according to thresholds as they are reported in the literature (Table 2), as weak, moderate and severe; and secondly, for each index a mean value was calculated

The classification reveals that the potential of the atmosphere for severe thunderstorms with hail is high for $90 \%$ of the events according to the $\mathrm{KO}$ index, for the $50 \%$ of the cases according to the HcTc and for the $30 \%$ according to the WBZ. For the TT, K and CAPE the probability is high for less than $10 \%$ of the cases.

Also, the values of the moderate category can give severe thunderstorms with hail in Cyprus for $76 \%$ of the cases according to the TT index and for $53 \%$ of the cases according to the $\mathrm{K}$ and $\mathrm{WBZ}$ index.

The calculation of the mean value of each index (Table 1) reveals that the atmosphere has moderate to high probability for severe thunderstorms with hail for all the indices, but for CAPE; this is probably due to the time difference between the flood event and the release of the radiosonde.

\section{Concluding remarks}

Flooding is a hazardous weather phenomenon and affects parts of Cyprus almost every year. During the thirteen-year period studied, 43 cases of flooding were reported mainly over urbanized areas. The dominant favorable weather conditions for flood events are either the presence of a frontal depression or a convectional weather type. Bearing in mind these two factors, flood events were classified into two categories; the "instability" category which comprises isolated flood events of short duration and the "frontal depression" category which comprises widespread flood events of long duration. The frontal depression flood events are typical during winter and autumn, when synoptic scale weather is more prominent. The instability flood events occur throughout the 
year but mostly during autumn and spring and the dominant triggering mechanism is the convective process, as most of the events occur within the warm period and during midday and afternoon. A significant contributor is the warm sea during the cold season, triggering and maintaining lower tropospheric convergence. The thermodynamic study has shown that the combination of KO, TT, WBZ and Hc Tc indices can be used as forecasting indices with good results.

Acknowledgements. This study was undertaken within the framework of project FLASH which is funded by the European Union (Sixth Framework Programme, Contract No. 036852).

Edited by: F. Stel and D. B. Giaiotti

Reviewed by: two anonymous referees

\section{References}

Blanchet, G.: Le temps au Liban, Approche d' une Climatologie Synoptique, Thèse 3ème Cycle, Lyon. T.I., 447 (text et tab.) \& T.II (Atlas), 1976.

El-Fandy, M. G.: Barometric Lows of Cyprus, Q. J. Roy. Meteor. Soc., 72, 291-306, 1946.

Houssos, E. E. and Bartzokas, A.: Extreme precipitation events in NW Greece, Adv. Geosci., 7, 91-96, 2006,

http://www.adv-geosci.net/7/91/2006/.
Jacovides, C. J. and Yonetani, T.: An evaluation of instability indices for thunderstorm prediction in Greater Cyprus, Weather Forecast., 5, 559-569, 1990.

Kallos, G. and Metaxas, D. A.: Synoptic processes for the formation of Cyprus lows, Riv. Meteorol. Aeronau., XL(2-3), 121138, 1980.

König, M: Atmosheric Instability Parameters Derived from MSG SEVIRI Observations, EUMETSAT Technical Memorandum No. 9, 2002.

Maheras, P.: A factorial analysis of Mediterranean precipitation, Arch. Meteor. Geophy. B., 36, 1-14, 1985.

Michaelides, S., Nicolaides, K., and Karacostas, T.: Statistical characteristics of the cold season depressions over the area of Cyprus, Meteorologický è,asopis 7, 61-66, 2004.

Michalopoulou, H. and Jacovides, C.:Instability Indices for Cyprus Area, Meteorol. Atmos. Phys., 37, 153-158, 1987.

Nicolaides, K.: Synoptic and dynamic study of the depression cases affected the wider area of Cyprus during cold months, $\mathrm{PhD}$ thesis, Aristotelian University, Thessaloniki, Greece, 2005 (in Greek).

Nicolaides, K., Michaelides, S., and Karacostas, T.: Spatial distribution of some dynamic parameters during the evolution of selected depressions over the area of Cyprus, Int. J. Climatol., 24, 1829-1844, 2004.

University of Wyoming: http://weather.uwyo.edu/upperair/ sounding.html, last access: 15 December 2007. 